\title{
Comparison of IRI-01cor, IRI-Plas 2017, NeQuick-2 and NIGTEC models with GPS-TEC measurements over Nigeria
}

\author{
A.A. Obafaye ${ }^{1},{ }^{*}$, D.I. Okoh ${ }^{1}$, A.O. Adewale ${ }^{2}$, B.C. Udochukwu ${ }^{3}$, A.B. Rabiu ${ }^{1}$ \\ ${ }^{1}$ Center for Atmospheric Research, National Space Research and Development Agency, \\ Kogi State University Campus, Anyigba, Nigeria. \\ ${ }^{2}$ Ionospheric \& Space Physics Laboratory, Department of Physics, University of Lagos, \\ Nigeria \\ ${ }^{3}$ Department of Physics, University of Agriculture, Makurdi, Nigeria \\ E mail (easyronke2@gmail.com).
}

\begin{abstract}
Accepted: 14 March 2020
Abstract. This work examines the performance of four ionospheric models for estimating Total Electron Content (TEC) over Nigeria. The observed Vertical TEC values retrieved from five GPS stations located between geographic latitudes $4.80^{\circ}$ and $12.47^{\circ} \mathrm{N}$ were analyzed and compared with corresponding values obtained from the International Reference Ionosphere (IRI-01corrected option), the IRI-Plasmasphere 2017, NeQuick-2 and Nigerian Total Electron Content (NIGTEC) models. NIGTEC model used in this work is a neural network based model developed at the Nigerian Centre for Atmospheric Research as a regional model, while the IRI-01cor, IRI-Plas 2017 and NeQuick are well-known global ionospheric models. We evaluated TEC from the four models at hourly levels for all the days of the year 2012 (sunspot number $\mathrm{Rz}=84.4$ ). TEC directly derived from the five GPS stations under consideration was also evaluated for all the days of the year. The paper also considered the performance of the models under geomagnetically quiet condition $(A p \leq 5)$. The NIGTEC model has shown better agreement with the observed VTEC when compared with the IRI-01cor, NEQUICK and IRI-Plas 2017 models especially during the pre-Sunrise period. With mean values of RMSE as 3.378 TECU and 3.8403 TECU for all days and geomagnetically quiet condition respectively, NIGTEC returned the lowest RMSE values at all conditions. The modelled TEC obtained from all the four models, at both geomagnetically disturbed and quiet times, follow the diurnal pattern of the observed GPS-TEC with variations in magnitudes. The NIGTEC model performed better than IRI01cor, NEQUICK and IRI-Plas 2017 even when only geomagnetically quiet condition was considered. The NeQuick and NIGTEC model correctly captured the annual distribution pattern of the observed GPS-TEC across the stations. This distribution was over-smoothed by the IRI and IRI-Plas models.
\end{abstract}

(c) 2020 BBSCS RN SWS. All rights reserved

Keywords: lonosphere, Models, GPS

\section{Introduction}

The ionosphere is defined as the ionized region of the atmosphere at a height between 50 and $1000 \mathrm{~km}$ that has very strong influence on high frequency radio propagation. The equatorial and low-latitude ionosphere is of interest to researchers because of the unique processes manifested in that region which includes; the plasma fountain, equatorial electrojet, and the equatorial ionization anomaly (EIA). The orientation of the geomagnetic field lines at the equator and the shift between the geographic and geomagnetic equators are known to be partly responsible for these observed features and their longitudinal variations (Bhuyan and Borah, 2007). EIA is characterized by a trough at the geomagnetic equator and two peaks (crests) on either side of the equator at about $15^{\circ}$ magnetic latitudes (Appleton, 1946). According to Mitra (1946), the depression exists because plasma produced by photo ionization at higher altitudes over the magnetic equator diffuses downwards and outwards to the north and south of the magnetic equator, leaving depletion at the equator.

TEC is a measure of the total number of electrons in the ionized plasma contained in a unit cross-sectional area $\left(1 \mathrm{~m}^{2}\right)$ between a GPS satellite and a GPS receiver (Habarulema et al. 2007). TEC is a useful parameter for users of transionospheric radio waves. In recent years, the transionospheric navigation systems have been the global positioning systems (GPS). The GPS is a satellite borne radio navigation system consisting of a network of 24-32 satellites in 6 orbital planes with 4 satellites in each plane. The GPS satellites orbit at an altitude of about $20,200 \mathrm{~km}$ with an orbital plane inclination of $55^{\circ}$ to the Earth's equator. It provides information globally and in all weather conditions in terms of position, time, and velocity. The GPS-TEC is an important parameter for the characterization of the ionosphere and a good indicator of the geographical distribution of the ionization and has been proposed as an input assimilative ionosphere models (Misra and Enge, 2006). As the F region forms the largest part of TEC, the expansion and variation of the EIA can be identified by the electron density.

Radio systems using signals from satellites that transverse the ionosphere experiences errors which are proportional to TEC. To reduce the effects of these errors, we need to measure or model TEC. Furthermore, the low number of GPS receivers installed around the low latitude region, poor maintenance, political unrest and lack of public infrastructures (e.g. epileptic power supply) have contributed to some problems encountered in the direct measurement of TEC. There are very scanty number of TEC measurement point in Nigeria with only about 20 GPS receivers over a landmass of about one million square kilometers, compared to over 1000 GPS facilities in Japan. Even some of the available stations in Nigeria do have downtime due to power outages and at times vandalisation. Incidentally, all the countries in the low latitude region share similar limitations with respect to observational data availability with Nigeria.

Estimation of TEC using models make data available at every location once the geographical coordinates and other needed parameters are provided. It is very necessary to develop forecasting/ predicting techniques, and to validate the models as they are revised especially in Nigeria and other low latitude regions, where the ionosphere shows a unique behaviour, due to its location near the magnetic equator. This is because of the very significant effects TEC variations have on radio communications like navigation, positioning, time transfer, radar, radio astronomy and space weather.

Ionospheric models are useful when it comes to forecasting and predicting the behavior of the ionosphere for locations and time instances where empirical observations are not available. The 
NeQuick model is based on the Di Giovanni-Radicella (DGR) model which was modified to give VTEC from ground to 1000 $\mathrm{km}$ consistent with the European Cooperation in the field of Scientific Technical Research (COST) 238 regional electron content (Di Giovanni and Radicella, 1990).

The International Reference Ionosphere (IRI) model is one of the most common ionospheric models that has wide acceptance as a standard for specifying ionospheric parameters across the globe (Bilitza, 1990). Yet, the most discussed limitation about the model, especially for researchers interested in comparing the model predictions with GNSS observations is that it computes ionospheric parameters only up to altitudes of $2000 \mathrm{~km}$ (Gulyaeva and Bilitza, 2012; Rabiu et al. 2014; Okoh et al. 2015; Arikan et al. 2016; Ezquer et al. 2017)

NIGTEC is a model of the ionospheric GNSS TEC over Nigeria $\left(2-15^{\circ} \mathrm{E}, 4-14^{\circ} \mathrm{N}\right)$ developed at the Nigerian Centre for Atmospheric Research (Okoh et al. 2016). The model can be used to estimate the ionospheric GNSS TEC at all locations over Nigeria. The model can generate the diurnal profiles for all the days in a particular year.

Many researchers have investigated the performance of a number of versions of NeQuick and International Reference Ionosphere (IRI) models in estimating or predicting TEC at different locations including Nigeria (MigoyaOrue' et al. 2008; Coisson et al. 2008; Bidaine and Warnant, 2010; Habarulema, 2010; Adewale et al. 2011, 2012; Okoh et al. 2012, 2015, 2016; Rabiu, et al. 2014)

Okoh et al. (2012) observed that the IRI TEC values compared well with the GPS observed TEC values at Nsukka, Nigeria $\left(6.87^{\circ}\right.$ $\mathrm{N}, 7.38^{\circ} \mathrm{E}$; dip latitude 2.97 ) with 0.9 correlation coefficients and root-mean square deviations generally around $20-50 \%$ for diurnal comparisons. Adewale et al. (2011) reported that IRI-2007 (NeQuick option) gave a relatively poor TEC prediction at Lagos (6.5N, 3.4E; dip latitude 3.03S), between 0200 and $0600 \mathrm{~h} \mathrm{LT}$, the TEC percentage deviation having values greater than $50 \%$ during all seasons considered in year 2009. In their findings, Rabiu et al. (2014) simultaneously studied the diurnal, seasonal, and annual TEC variations at some locations in Nigeria. They reported that the IRI and NeQuick modelled values followed the diurnal and seasonal variation patterns of the observed values of VTEC. However, IRI model produced the best results at all locations, with the exception of one station (RUST).

Olwendo et al. (2013) compared the IRI-TEC values with TEC derived from the International GNSS Service (IGS) receivers at Malindi (mal2: $2.9^{\circ} \mathrm{S}, 40.1^{\circ} \mathrm{E}$, dip -26.813), Kasarani (rcmn: $36.89^{\circ} \mathrm{E}, 1.20^{\circ} \mathrm{S}$, dip -23.970 ), Eldoret (moiu: $35.3^{\circ} \mathrm{E}, 0.3^{\circ} \mathrm{N}$, dip -21.037) and GPS-SCINDA $\left(36.8^{\circ} \mathrm{E}, 1.3^{\circ} \mathrm{S}\right.$, dip -24.117) receiver located in Nairobi for the period 2009-2011. They reported that both the GPS-TEC and IRI-TEC depict a similar trend in the monthly and seasonal variations. They, however, opined that seasonal averages show that IRI-TEC values are higher than the GPS-TEC.

Tariku (2015) in his work on TEC prediction performance of the IRI-2012 model over Ethiopia during the rising phase of solar cycle 24 (2009-2011) revealed that the highest diurnal VTEC peak values were generally observed during equinoctial months, while the lowest peak values were observed during the June solstice months. The overall results showed that using the IRI-2012 model with the NeQuick option for the topside electron density is generally better in estimating diurnal, monthly, and seasonal VTEC variations.

In all of the previous works examined, only Okoh et al. (2016) compared the VTEC predictions from the regional NIGTEC model developed in their work with those from the IRI and NeQuick models and concluded that the NIGTEC model performed better in terms of the predicting errors. The IRI-Plas model is considered to be a better version of IRI model as it extends to the plasmasphere altitude (Arikan et al. 2017). The present work attempts to compare the performance of the IRI,
NeQuick2, IRI-Plas 2017 and NIGTEC models with the measured GPS-TEC at five (5) locations in Nigeria located within equatorial anomaly region. This is the first time that the performance of NIGTEC model is compared with the improved IRI-Plas 2017 model.

\section{Data and Method of Analysis}

\subsection{Evaluation of TEC}

The raw GPS-TEC data were obtained from the office of the Surveyor General of the Federation (OSGOF) www.osgof.org in the Receiver Independent Exchange (RINEX) format for the year 2012. The uncorrected Slant Total Electron Content (STEC) obtained from the GPS satellite is then converted to Vertical Total Electron Content (VTEC) using the GPS-TEC analysis application software, version 2.2 (Gopi, 2010) developed by Gopi Seemala of the Institute for Scientific Research, Boston College, USA. This was achieved using the expression (Breed et al.1997):

$$
V T E C=\frac{S T E C-\left(b_{r}-b_{s}\right)}{S(E)}
$$

where $b_{r}$ and $b_{s}$ are respectively the receiver and satellite biases, and the STEC is the uncorrected slant TEC measured by the receiver, while VTEC is the vertical TEC at the ionospheric pierce point (IPP). The $\mathrm{S}(\mathrm{E})$ is the mapping function as defined by Mannucci et al. (1993) as follows:

$$
S(E)=\frac{1}{\cos (z)}\left[1-\left(\frac{R_{E} \cos (E)}{R_{E}-h_{s}}\right)^{2}\right]
$$

where $\mathrm{z}, \mathrm{R}_{\mathrm{E}}, \mathrm{E}, \mathrm{h}_{\mathrm{s}}$ are the zenith angle of the satellite as seen from the observing station, radius of the Earth, elevation angle in radians, and altitude of the thin layer above the surface of the Earth (taken as $350 \mathrm{~km}$ ), respectively.

Equations 1 and 2 have been incorporated in the development of the GPS-TEC analysis application software, developed by Gopi Seemala. Daily TEC Values were obtained from IRI-2016 model (NeQuick model) by developing an appropriate MATLAB script. Table 1 shows the coordinates of the five stations engaged in this study. Map of Nigeria showing the locations of the GPS receivers and the magnetic equator over Nigeria is shown in Fig.1. NeQuick data were generated from the NeQuick source code package which uses some input parameters to generate hourly VTEC in TEC units (TECU). The NIGTEC model was used to obtain the hourly profiles of the ionospheric GNSS TEC for all days at the selected locations over Nigeria.

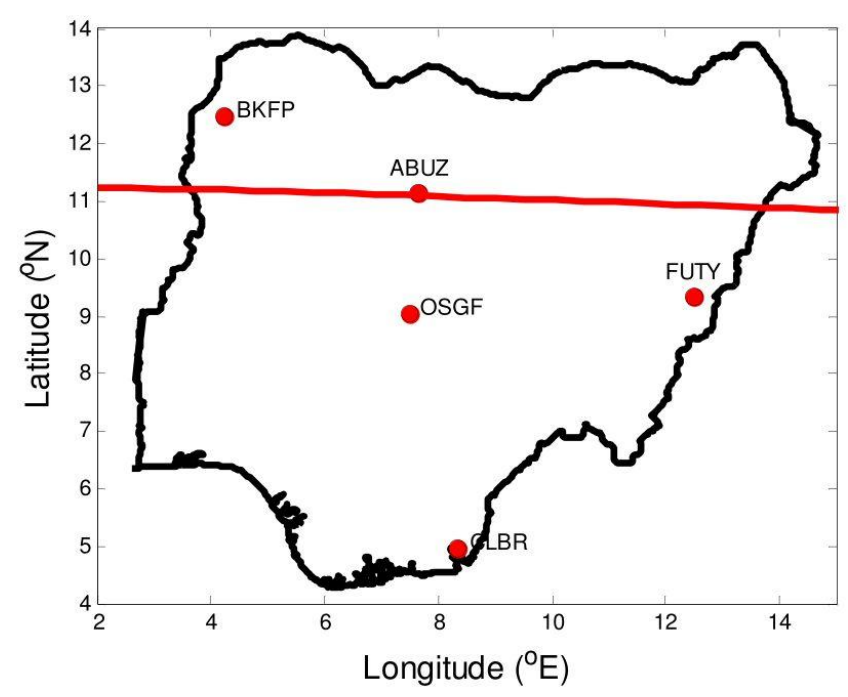

Fig. 1. Map of Nigeria showing the locations of the GPS receivers over Nigeria (the magnetic equator is indicated with the red line) 
Table 1. Coordinates of GPS receiver locations.

\begin{tabular}{lllllll}
\hline $\begin{array}{c}\text { Station } \\
\text { code }\end{array}$ & Location & $\begin{array}{c}\text { Geo. } \\
\text { lat } \\
\left({ }^{\circ} \mathrm{N}\right)\end{array}$ & $\begin{array}{c}\text { Geo. } \\
\text { Long } \\
\left({ }^{\circ} \mathrm{E}\right)\end{array}$ & $\begin{array}{c}\text { Mag. } \\
\text { Lat } \\
\left({ }^{\circ} \mathrm{N}\right)\end{array}$ & $\begin{array}{c}\text { Mag. } \\
\text { Long } \\
\left({ }^{\circ} \mathrm{E}\right)\end{array}$ & $\begin{array}{c}\text { Dip } \\
\text { Angle } \\
\left({ }^{\circ}\right)\end{array}$ \\
\hline ABUZ & Kaduna & 11.15 & 7.65 & -0.62 & 79.75 & 1.17 \\
BKFP & Kebbi & 11.15 & 7.64 & 0.72 & 76.62 & 1.4 \\
CLBR & Calabar & 12.47 & 4.23 & -4.30 & 80.09 & 17.13 \\
FUTY & Yola & 9.35 & 12.50 & -1.32 & 84.31 & 5.34 \\
OSGF & F.C.T & 9.03 & 7.49 & -1.60 & 79.49 & 6.32 \\
\hline
\end{tabular}

A minimum elevation angle of $30^{\circ}$ is used in order to eliminate the effect due to multipath. A MATLAB script was developed to average the data into hourly values for all the stations. The hourly values of VTEC for all the days of the year 2012 (1 January to 31 December) were evaluated and analysed in local time (LT). Daily hourly IRI-VTEC values were obtained from IRI-2016 model (01 corrected option) by developing an appropriate MATLAB script. An altitude of $2000 \mathrm{~km}$ was selected as the upper boundary of electron density profiles and the B0 Table option for the bottomside electron density shape parameter.

For the NeQuick model, the Di Giovanni-Radicella (DGR) model (Di Giovanni and Radicella, 1990), was used to obtain the VTEC from ground to $1000 \mathrm{~km}$ consistent with the European Cooperation in the field of Scientific Technical Research (COST) 238 regional electron content. The NeQuick source code package engaged in this study included the following inputs: height $(\mathrm{km})$, latitude (degrees $\mathrm{N}$ ), longitudes (degrees $\mathrm{E})$, months (1...12), $10.7 \mathrm{~cm}$ solar radio flux (flux units) and universal Time (hours). The output gave us the NeQuick-VTEC.
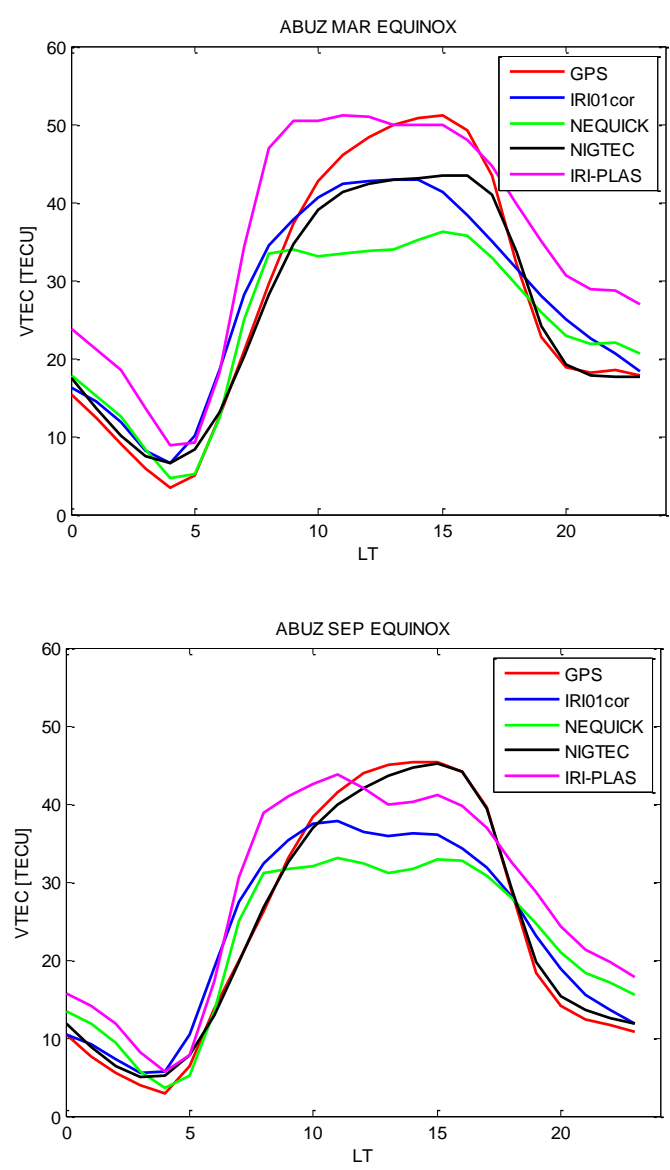

For the NIGTEC which is a model of the ionospheric GNSS TEC over Nigeria $\left(2-15^{\circ} \mathrm{E}, 4-14^{\circ} \mathrm{N}\right)$, we used all the available days of the months in 2012 for the observed and predicted averages in all the five stations.

The hourly values of GPS-TEC, IRI-TEC, NEQUICK-TEC and NIGTEC were grouped into seasons. Seasonal effects were investigated using Lloyd's seasonal classification according to Eleman (1973) and modified by Rabiu et al. (2007); March Equinox (MAREQUI) (March, April) June Solstice (JUNSOLS) (May, June, July, August) September Equinox (SEPEQUI) (September, October), and December Solstice (DECSOLS) (November, December, January, February) for the year 2012. The seasonal mean hourly values of TEC were obtained by taking the averages of the hourly TEC across the months in each particular season. Thus, Figures 2, 3, 4, 5, and 6 presented the seasonal mean hourly variations of measured GPS-TEC and modelled TEC at ABUZ, BKFP, CLBR, FUTY and OSGF respectively. The hourly values of GPS-TEC, IRI01cor-TEC, NEQUICK-TEC, NIGTEC and IRI-Plas 2017 were plotted against the days of the year as contour maps and presented as Figures 7, 8, 9, 10, and 11 for ABUZ, BKFP, CLBR, FUTY and OSGF respectively.

The root-mean-square error (RMSE) was computed to determine how well the models predict the GPS-TEC:

$$
R M S E=\sqrt{\left.\sum_{i=1}^{N} \frac{1}{N}\left(V T E C_{s b s}-V T E C_{\text {mod }}\right)^{2}\right)}
$$

where $\mathrm{N}$ is the number of data points and VTECobs and VTECmod are the observed and modelled VTEC values, respectively. Table 2 displays the values of the root mean square errors for IRI-01 cor, NeQuick, NIGTEC and IRI-Plas2017 models at all stations for various seasons.


Figure 2. Seasonal mean hourly variations of measured GPS-TEC and modelled TEC at ABUZ 



Figure 3. Seasonal mean hourly variations of measured GPS-TEC and modelled TEC at BKFP
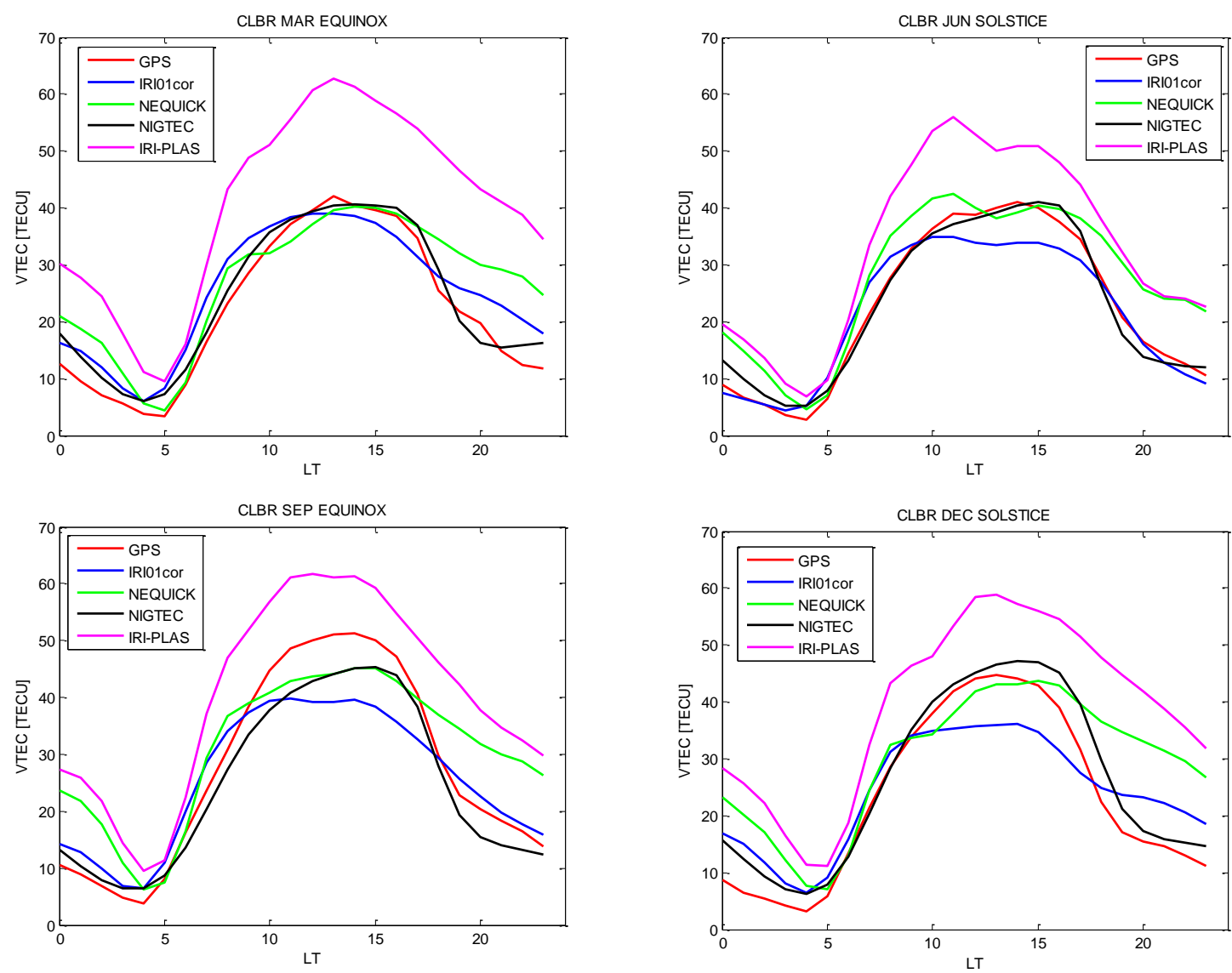

Figure 4. Seasonal mean hourly variations of measured GPS-TEC and modelled TEC at CLBR 



Figure 5. Seasonal mean hourly variations of measured GPS-TEC and modelled TEC at FUTY.
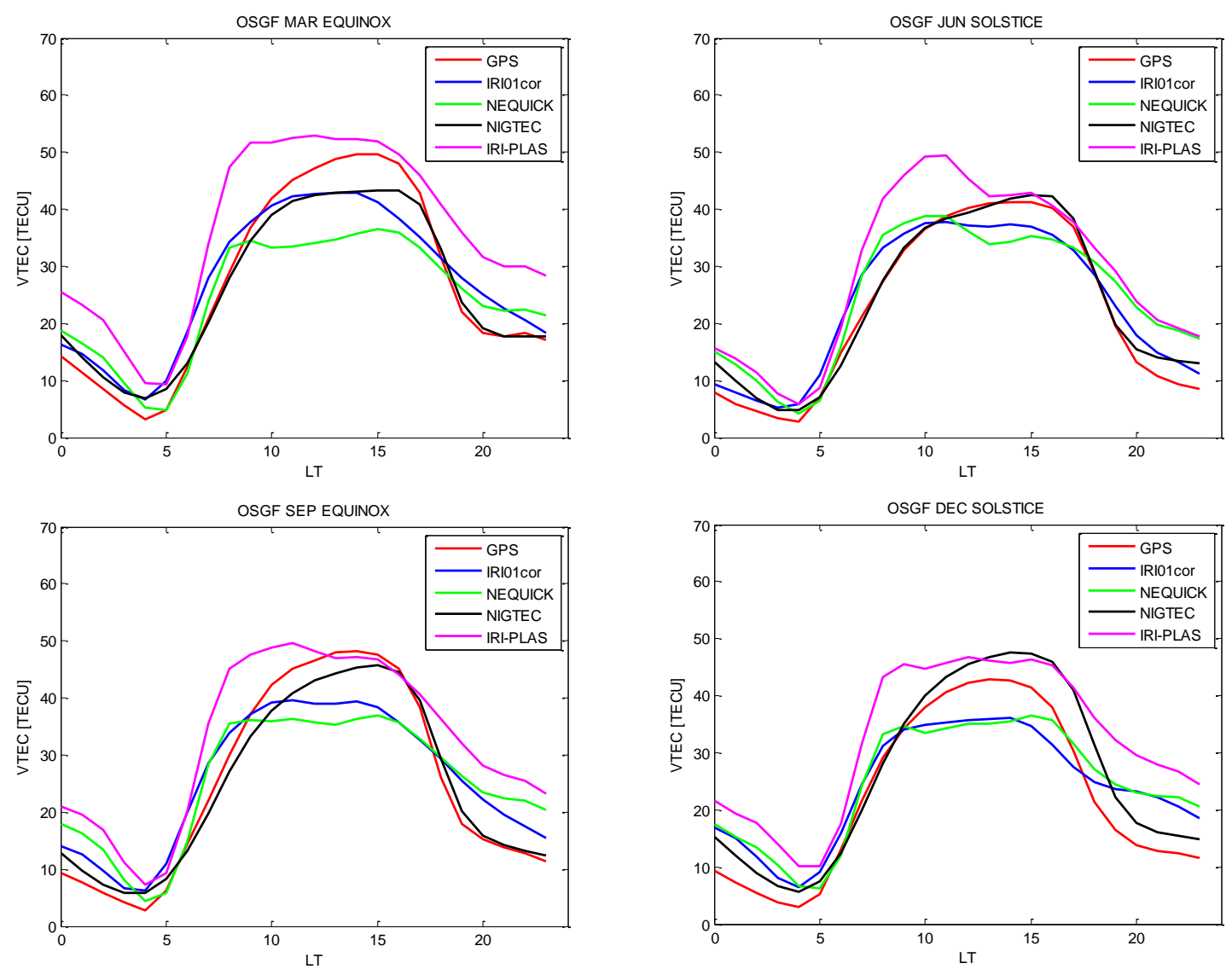

Figure 6. Seasonal mean hourly variations of measured GPS-TEC and modelled TEC at OSGF. 


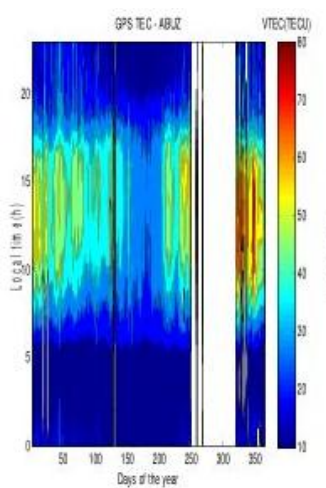

(a)

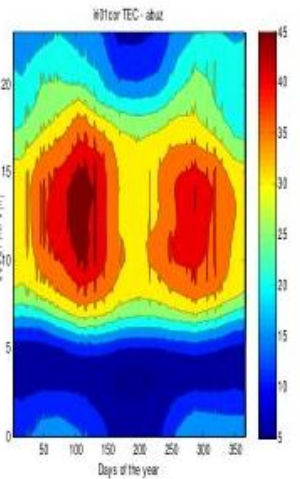

(b)

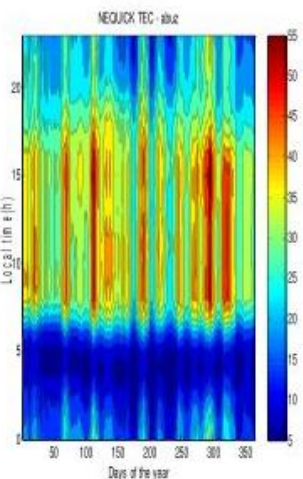

(c)

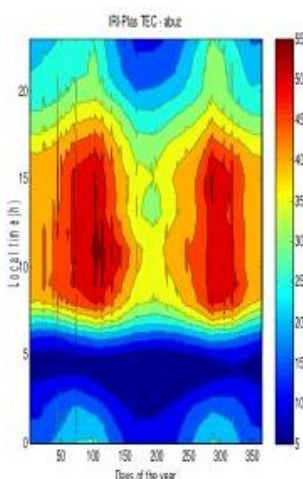

(d)

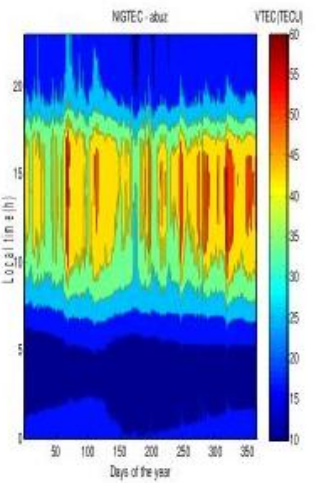

(e)

Figure 7. Contour maps showing hourly values of (a) GPS-TEC, (b) IRI01cor-TEC, (c) NEQUICK-TEC, (d) NIGTEC and (e) IRI-Plas 2017 for all the days of year 2012 at ABUZ (The white portion indicates unavailability of data)

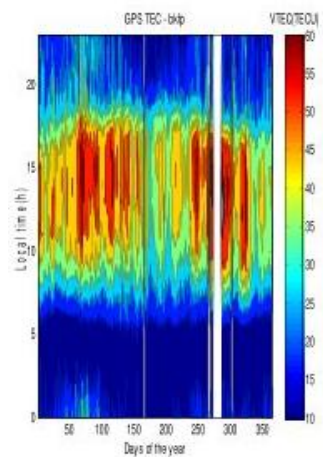

(a)

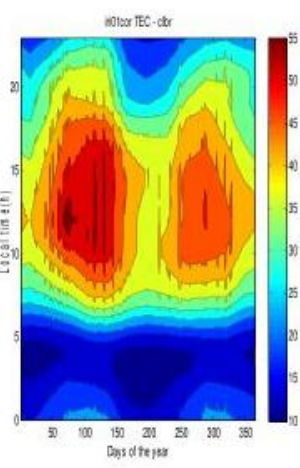

(b)

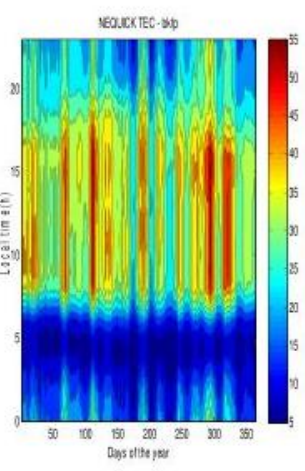

(c)

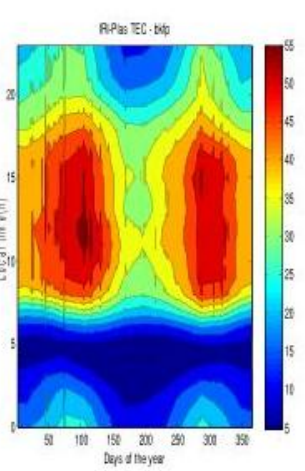

(d)

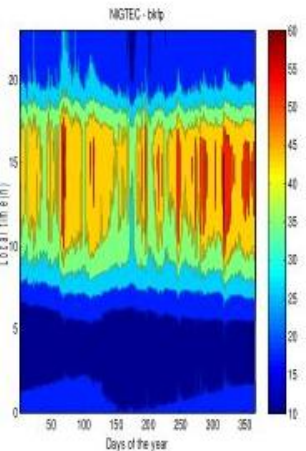

(e)

Figure 8. Contour maps showing hourly values of (a) GPS-TEC, (b) IRI01cor-TEC, (c) NEQUICK-TEC, (d) NIGTEC and (e) IRI-Plas 2017 for all the days of year 2012 at BKFP (The white portion indicates unavailability of data)

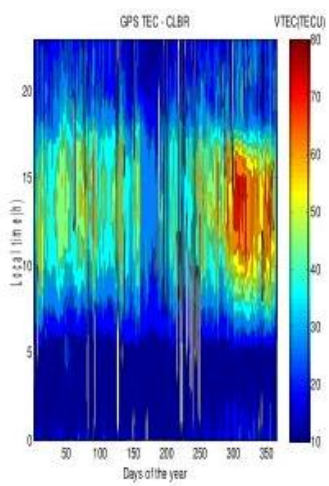

(a)

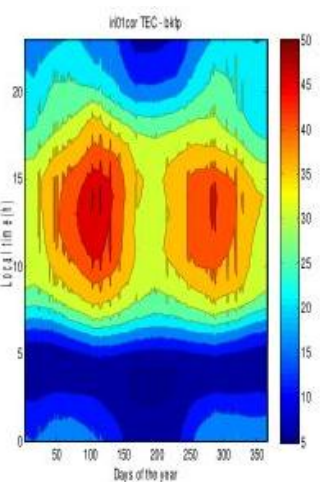

(b)

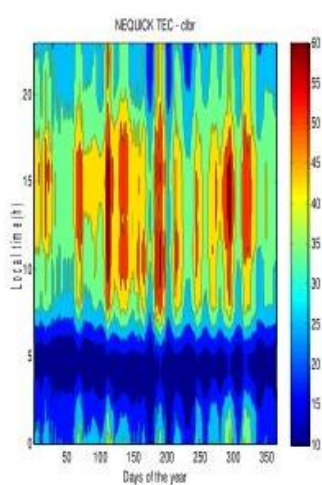

(c)

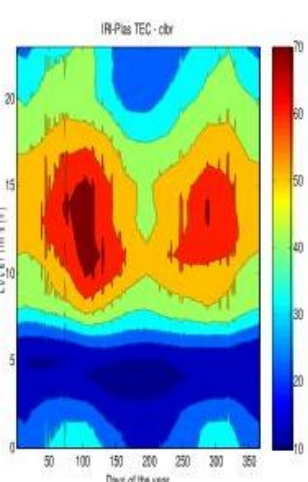

(d)

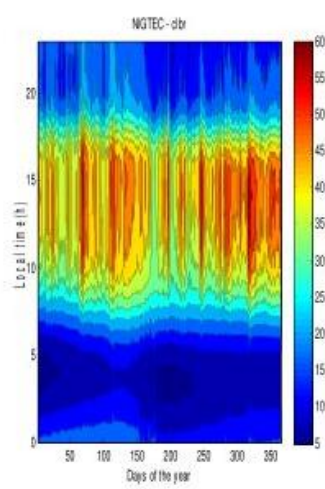

(e)

Figure 9. Contour maps showing hourly values of (a) GPS-TEC, (b) IRI01cor-TEC, (c) NEQUICK-TEC, (d) NIGTEC and (e) IRI-Plas 2017 for all the days of year 2012 at CLBR

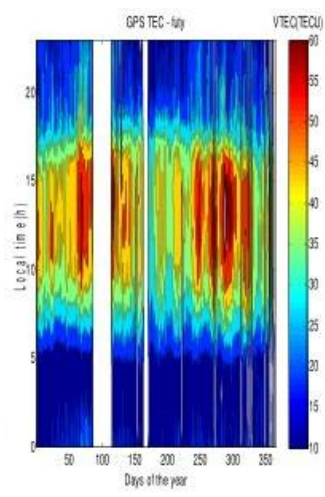

(a)

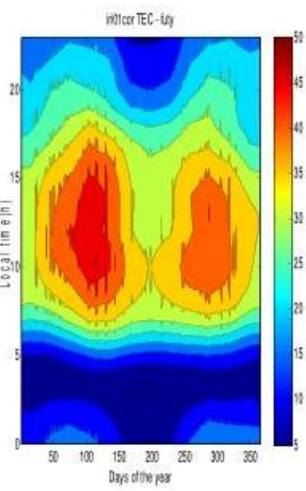

(b)

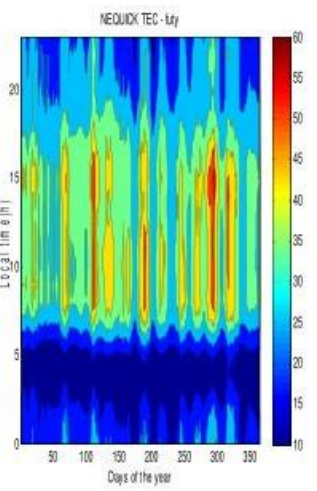

(c)

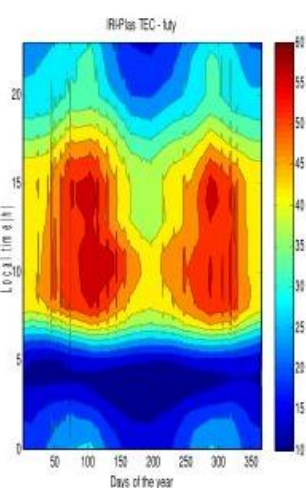

(d)

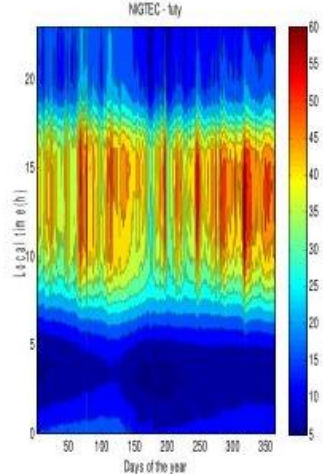

(e)

Figure 10. Contour maps showing hourly values of (a) GPS-TEC, (b) IRI01cor-TEC, (c) NEQUICK-TEC, (d) NIGTEC and (e) IRI-Plas 2017 for all the days of year 2012 at FUTY (The white portion indicates unavailability of data) 


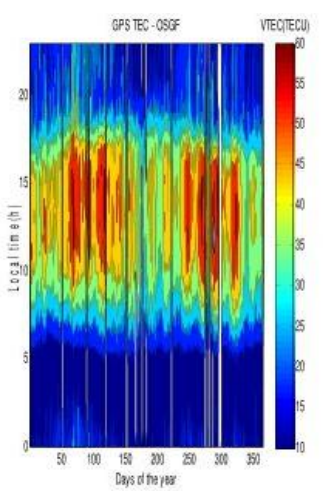

(a)

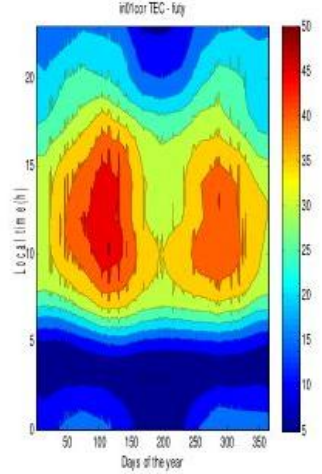

(b)

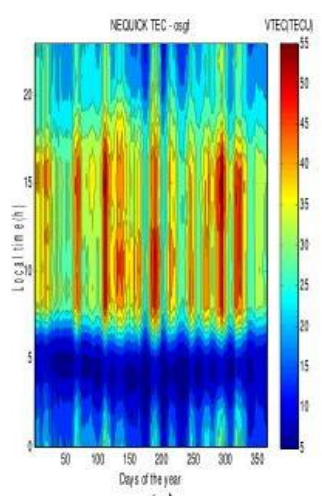

(c)

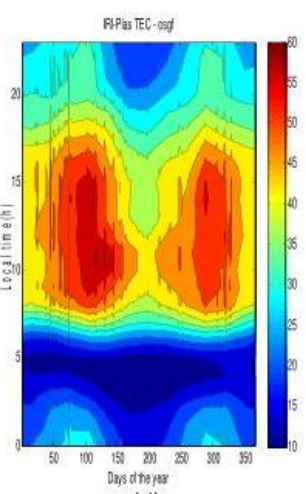

(d)

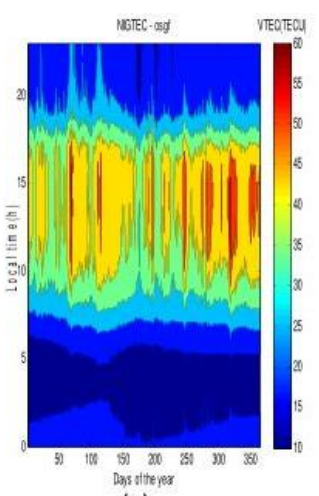

(e)

Figure 11. Contour maps showing hourly values of (a) GPS-TEC, (b) IRI01cor-TEC, (c) NEQUICK-TEC, (d) NIGTEC and (e) IRI-Plas 2017 for all the days of year 2012 at OSGF

Table 2: Root mean square errors for IRI-01cor, NeQuick, NIGTEC and IRI-Plas 2017 models.

\begin{tabular}{|c|c|c|c|c|c|}
\hline \multirow{2}{*}{$\begin{array}{c}\text { STATION } \\
\text { CODE }\end{array}$} & \multirow[b]{2}{*}{ SEASONS } & \multicolumn{4}{|c|}{ RMSE (TECU) } \\
\hline & & $\begin{array}{l}\text { IRI- } \\
01 C O R\end{array}$ & NEQUICK & NIGTEC & IRI-PLAS \\
\hline \multirow[t]{4}{*}{$A B \cup Z$} & DECEMBER SOLSTICE & 5.765 & 5.398 & 4.575 & 8.321 \\
\hline & MARCH EQUINOX & 5.401 & 8.227 & 3.697 & 8.566 \\
\hline & JUNE SOLSTICE & 4.053 & 6.191 & 2.096 & 6.344 \\
\hline & SEPTEMBER EQUINOX & 5.390 & 7.250 & 1.134 & 6.538 \\
\hline \multirow[t]{4}{*}{ BKFP } & DECEMBER SOLSTICE & 5.883 & 5.631 & 4.175 & 8.653 \\
\hline & MARCH EQUINOX & 5.265 & 8.207 & 3.411 & 8.721 \\
\hline & JUNE SOLSTICE & 3.767 & 7.318 & 2.010 & 5.996 \\
\hline & SEPTEMBER EQUINOX & 5.879 & 7.061 & 2.409 & 7.815 \\
\hline \multirow[t]{4}{*}{ CLBR } & DECEMBER SOLSTICE & 8.229 & 9.920 & 3.825 & 17.110 \\
\hline & MARCH EQUINOX & 9.262 & 7.246 & 2.734 & 19.268 \\
\hline & JUNE SOLSTICE & 5.130 & 6.411 & 1.928 & 11.115 \\
\hline & SEPTEMBER EQUINOX & 6.775 & 8.028 & 4.177 & 13.242 \\
\hline \multirow[t]{4}{*}{ FUTY } & DECEMBER SOLSTICE & 6.074 & 6.167 & 3.621 & 9.311 \\
\hline & MARCH EQUINOX & 5.514 & 7.778 & 3.823 & 9.369 \\
\hline & JUNE SOLSTICE & 4.697 & 6.203 & 2.624 & 8.413 \\
\hline & SEPTEMBER EQUINOX & 6.679 & 7.746 & 3.221 & 8.952 \\
\hline \multirow[t]{4}{*}{ OSGF } & DECEMBER SOLSTICE & 4.981 & 6.462 & 4.707 & 10.036 \\
\hline & MARCH EQUINOX & 5.458 & 7.699 & 3.272 & 10.036 \\
\hline & JUNE SOLSTICE & 4.656 & 6.079 & 2.287 & 8.044 \\
\hline & SEPTEMBER EQUINOX & 6.624 & 8.135 & 3.037 & 9.207 \\
\hline MEAN & & 8.222 & 7.760 & 3.378 & 9.731 \\
\hline
\end{tabular}

\subsection{Evaluation of TEC values at quiet condition only}

The hourly values of GPS-TEC, IRI-TEC, NEQUICK-TEC and NIGTEC obtained in section 2.1 were extracted for 10 international quiet days in every month of the year 2012. The international quiet days engaged in this work were obtained from the World Data Center, Kyoto (http://wdc.kugi.kyotou.ac.jp/kp/index.html). This becomes necessary in order to ascertain the performance of various models under geomagnetically quiet condition. The obtained hourly values of GPS-TEC, IRI-TEC, NEQUICK-TEC and NIGTEC on the quiet days were grouped into Llyod's seasons as described in section 2.1 , and their mean seasonal hourly values are plotted against local time as Figures 12, 13,14, 15, and 16 at ABUZ, BKFP, CLBR, FUTY and OSGF respectively. The standard deviation and the root-mean-square error (RMSE) were computed for each season across the stations and presented as Tables 3 and 4 respectively. Table 5 presents the annual mean of the RMSE of different models at quiet condition with the values when all the days of the year 2012 were considered, hereafter referred to as mixed condition. Standard Deviation of hourly TEC ' $\sigma$ ' for quiet days engaged in this work was computed using equation 4 . This is the absolute difference between all 24- hour GPS observations and the corresponding model values computed for all the quiet days used in those seasons.

$$
\begin{aligned}
\text { Standard } & \sigma=\sqrt{\frac{1}{n-1} \sum_{i=1}^{n}\left(V T E C_{i}-\mu\right)^{2}} \\
\mu & =\frac{1}{n} \sum_{i=1}^{n}\left(V T E C_{i}\right)
\end{aligned}
$$

where $\mathrm{i}=1,2,3 \ldots \mathrm{n}$ and $\mathrm{n}$ is the number of quiet days used in the seasons multiplied by 24 hours for each of the days and $\mu$ is the mean VTEC. 

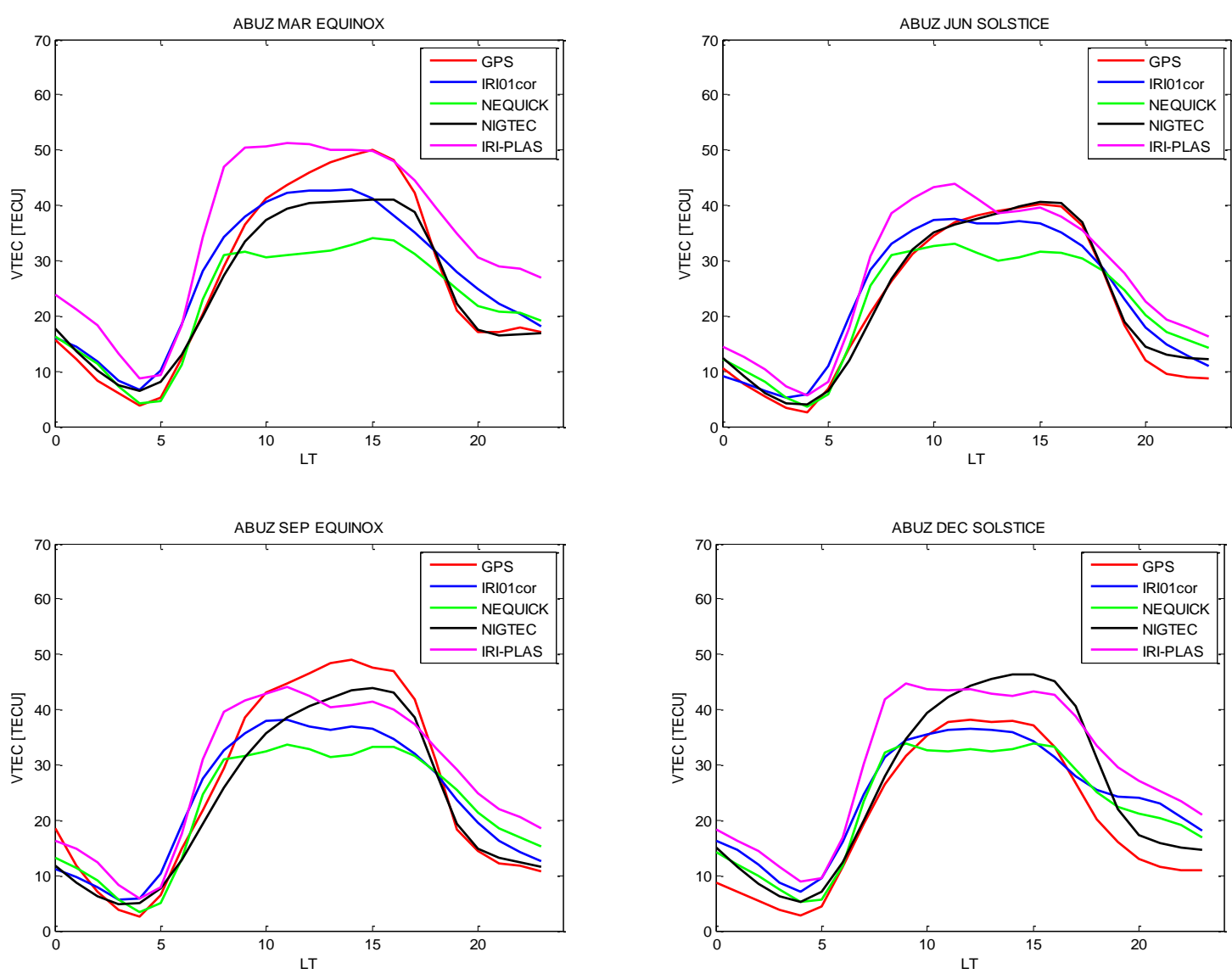

Fig 12. Seasonal mean hourly variations of measured GPS-TEC and modelled TEC on quiet condition only at ABUZ
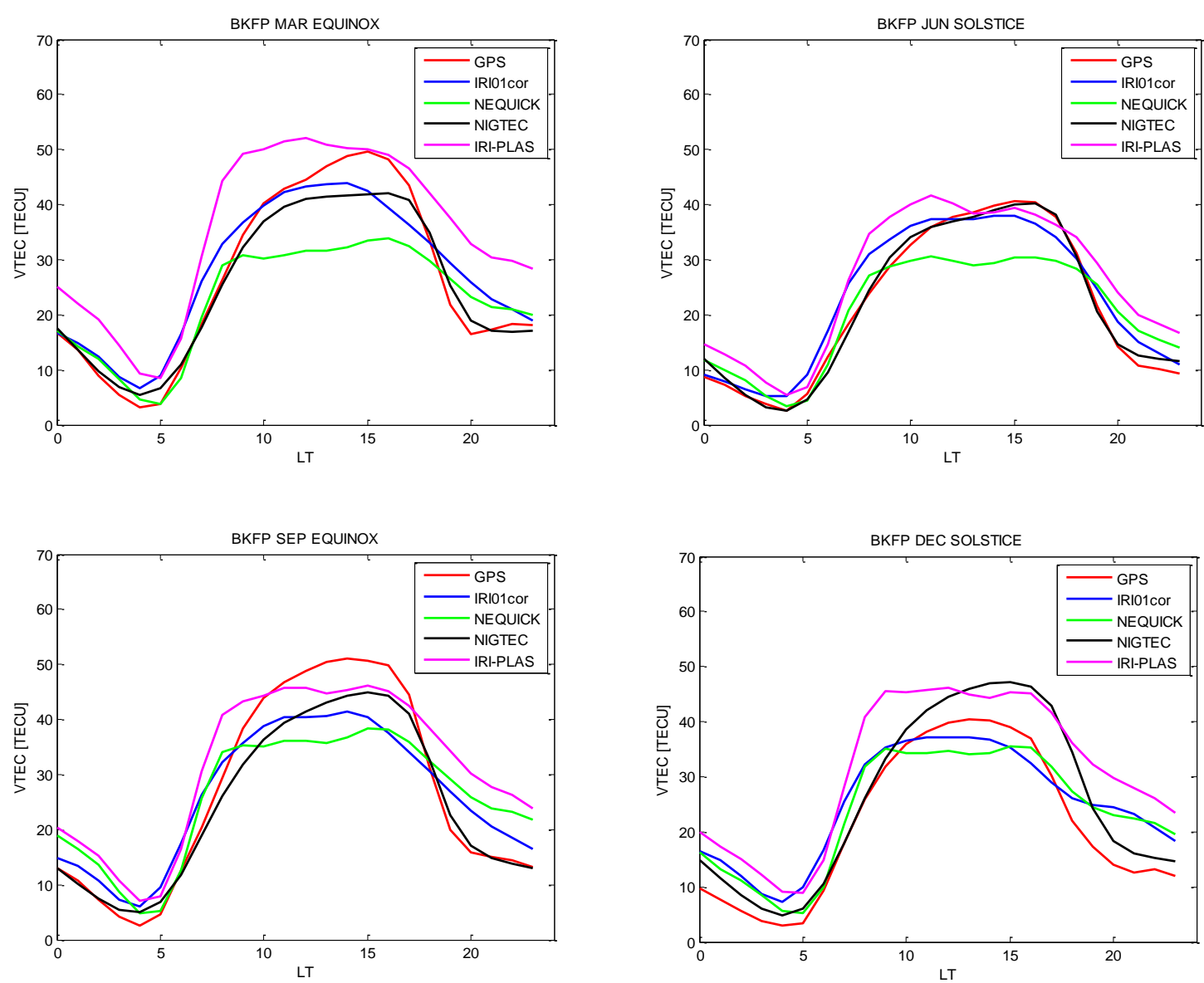

Fig 13. Seasonal mean hourly variations of measured GPS-TEC and modelled TEC on quiet condition only at BKFP 

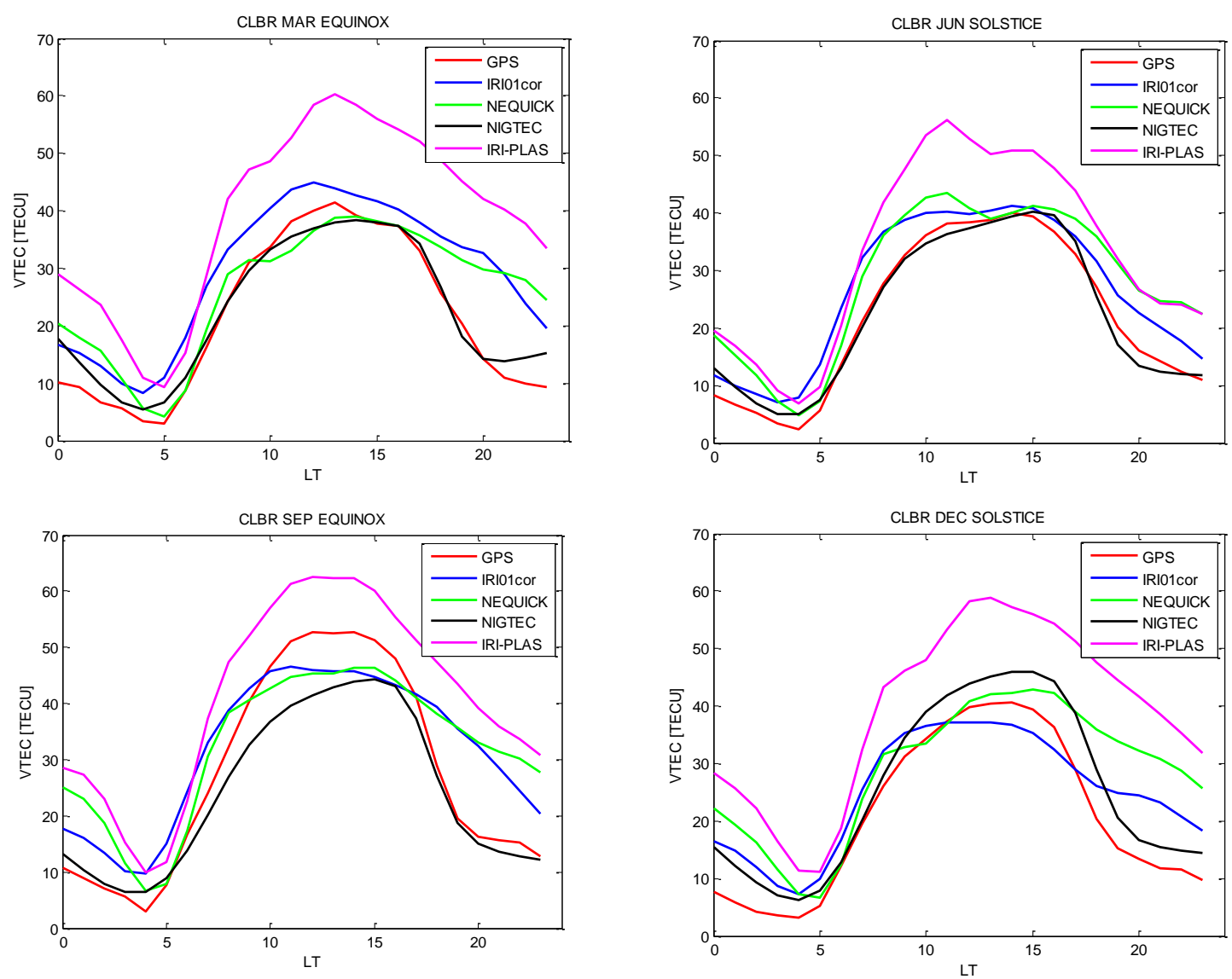

Fig 14. Seasonal mean hourly variations of measured GPS-TEC and modelled TEC on quiet condition only at CLBR
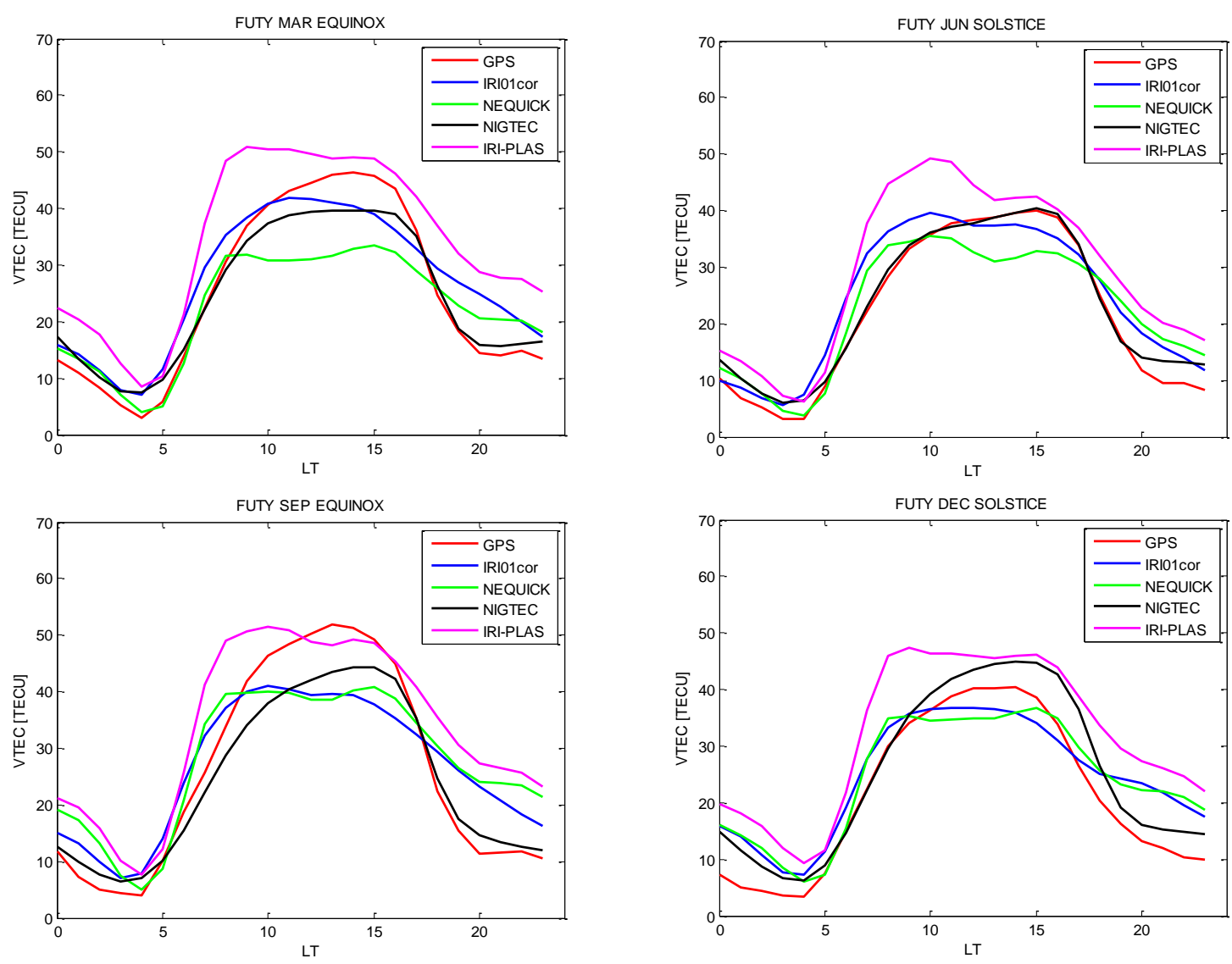

Fig 15. Seasonal mean hourly variations of measured GPS-TEC and modelled TEC on quiet condition only at FUTY 
Table 3. Standard deviations for IRI-01cor, NeQuick, NIGTEC and IRI-Plas 2017 models for geomagnetically quiet days only.

\begin{tabular}{|c|c|c|c|c|c|}
\hline \multirow[b]{2}{*}{$\begin{array}{l}\text { STATION } \\
\text { CODE }\end{array}$} & \multirow[b]{2}{*}{ SEASONS } & \multicolumn{4}{|c|}{ Standard deviation (TECU) } \\
\hline & & IRI-01COR & NEQUICK & NIGTEC & IRI-PLAS \\
\hline \multirow[t]{4}{*}{ OSGF } & DECEMBER SOLSTICE & 3.5642 & 3.5429 & 3.1699 & 3.9866 \\
\hline & MARCH EQUINOX & 2.8519 & 4.944 & 1.8453 & 4.5619 \\
\hline & JUNE SOLSTICE & 2.5178 & 2.6282 & 0.9433 & 4.0919 \\
\hline & SEPTEMBER EQUINOX & 2.9084 & 3.7791 & 2.2902 & 5.8773 \\
\hline \multirow[t]{4}{*}{ FUTY } & DECEMBER SOLSTICE & 2.8944 & 3.2198 & 2.5479 & 3.5794 \\
\hline & MARCH EQUINOX & 2.5396 & 4.6596 & 1.8919 & 4.4543 \\
\hline & JUNE SOLSTICE & 2.5930 & 2.6823 & 1.4343 & 4.4558 \\
\hline & SEPTEMBER EQUINOX & 3.3386 & 4.0192 & 2.7859 & 5.5079 \\
\hline \multirow[t]{4}{*}{ CLBR } & DECEMBER SOLSTICE & 5.0563 & 6.9021 & 2.3523 & 6.3755 \\
\hline & MARCH EQUINOX & 4.4214 & 5.8367 & 1.8999 & 6.3045 \\
\hline & JUNE SOLSTICE & 2.7415 & 3.7304 & 1.0942 & 3.4642 \\
\hline & SEPTEMBER EQUINOX & 3.8446 & 5.5515 & 3.5484 & 5.5252 \\
\hline \multirow[t]{4}{*}{ BKFP } & DECEMBER SOLSTICE & 2.6458 & 2.5172 & 3.4396 & 3.6886 \\
\hline & MARCH EQUINOX & 2.9378 & 5.6359 & 2.1451 & 4.8749 \\
\hline & JUNE SOLSTICE & 1.9139 & 3.2336 & 0.8974 & 3.2357 \\
\hline & SEPTEMBER EQUINOX & 3.1320 & 4.2096 & 2.7769 & 4.0632 \\
\hline \multirow[t]{4}{*}{$A B \cup Z$} & DECEMBER SOLSTICE & 2.7426 & 2.3372 & 3.5053 & 3.4250 \\
\hline & MARCH EQUINOX & 2.8430 & 5.8310 & 2.6333 & 4.8819 \\
\hline & JUNE SOLSTICE & 2.0278 & 3.0650 & 1.0752 & 3.7853 \\
\hline & SEPTEMBER EQUINOX & 3.6596 & 5.3936 & 2.3434 & 3.3306 \\
\hline
\end{tabular}
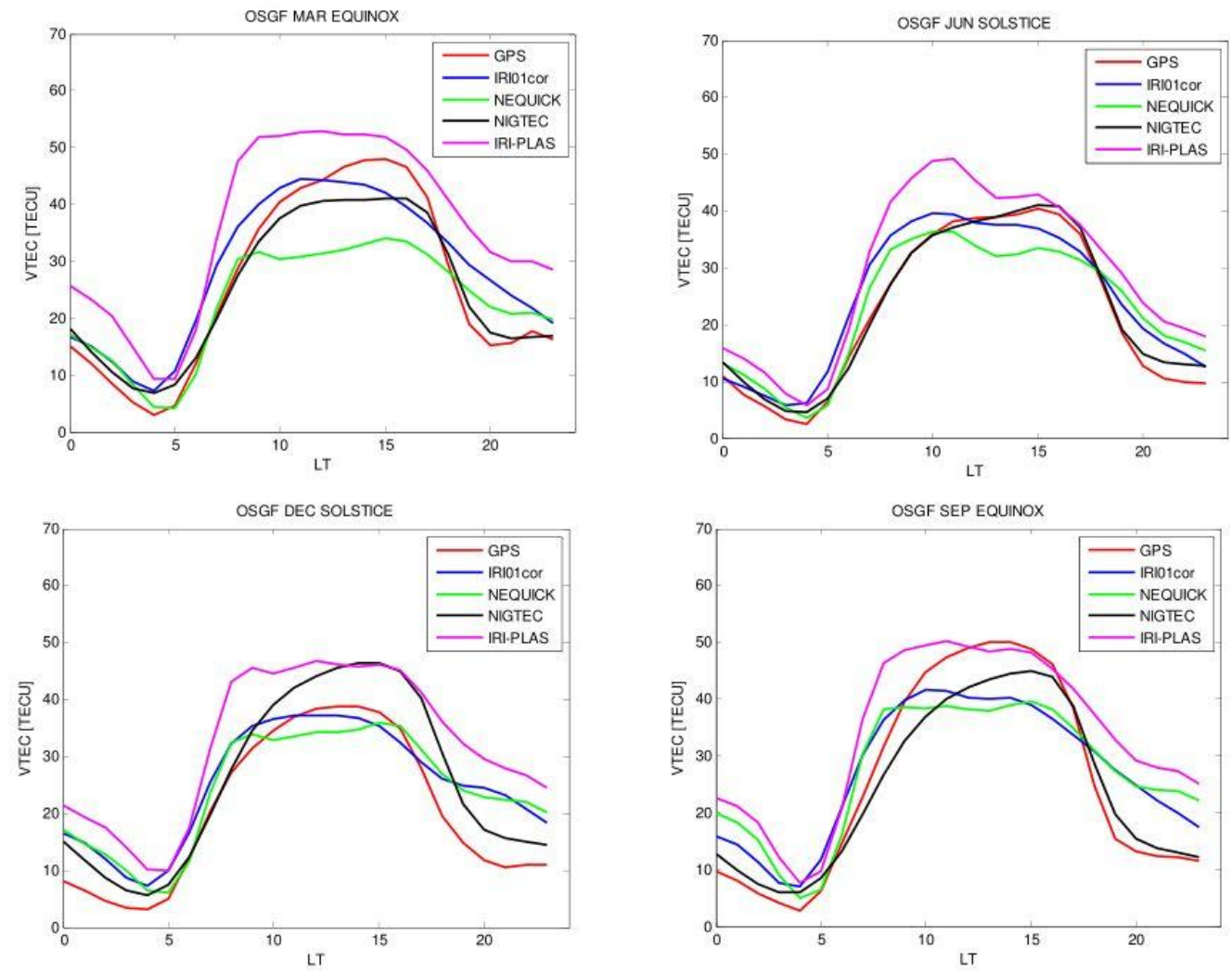

Fig 16. Seasonal mean hourly variations of measured GPS-TEC and modelled TEC on quiet condition only at OSGF 
Table 4: Root mean square errors for IRI-01cor, NeQuick, NIGTEC and IRI-Plas 2017 models for geomagnetically quiet days only

\begin{tabular}{|c|c|c|c|c|c|}
\hline \multirow{2}{*}{$\begin{array}{l}\text { STATION } \\
\text { CODE }\end{array}$} & \multirow[t]{2}{*}{ SEASONS } & \multicolumn{4}{|c|}{ RMSE (TECU) } \\
\hline & & IRI-01COR & NEQUICK & NIGTEC & IRI-PLAS \\
\hline \multirow[t]{4}{*}{$\mathrm{ABUZ}$} & DECEMBER SOLSTICE & 5.5006 & 4.9988 & 6.3263 & 9.9949 \\
\hline & MARCH EQUINOX & 5.1333 & 8.4272 & 3.9385 & 9.2932 \\
\hline & JUNE SOLSTICE & 3.8935 & 5.4438 & 1.5922 & 6.5953 \\
\hline & SEPTEMBER EQUINOX & 6.6907 & 8.6931 & 3.9947 & 6.4636 \\
\hline \multirow[t]{4}{*}{ BKFP } & DECEMBER SOLSTICE & 5.5864 & 5.4328 & 5.5891 & 3.6886 \\
\hline & MARCH EQUINOX & 5.0121 & 8.3091 & 4.8749 & 9.8895 \\
\hline & JUNE SOLSTICE & 3.4597 & 5.7089 & 1.4154 & 5.9886 \\
\hline & SEPTEMBER EQUINOX & 6.4404 & 8.5230 & 4.1982 & 7.9591 \\
\hline \multirow[t]{4}{*}{ CLBR } & DECEMBER SOLSTICE & 9.5522 & 10.5688 & 5.1658 & 19.1240 \\
\hline & MARCH EQUINOX & 8.9589 & 8.4063 & 2.9675 & 18.8610 \\
\hline & JUNE SOLSTICE & 5.3672 & 7.2763 & 1.9792 & 11.5330 \\
\hline & SEPTEMBER EQUINOX & 8.1522 & 9.6421 & 5.5981 & 14.2851 \\
\hline \multirow[t]{4}{*}{ FUTY } & DECEMBER SOLSTICE & 5.8268 & 6.0254 & 4.7132 & 11.0382 \\
\hline & MARCH EQUINOX & 5.4018 & 7.5023 & 3.5430 & 10.0622 \\
\hline & JUNE SOLSTICE & 4.6756 & 5.1693 & 2.1175 & 8.6895 \\
\hline & SEPTEMBER EQUINOX & 7.5967 & 8.5777 & 3.5430 & 9.8414 \\
\hline \multirow[t]{4}{*}{ OSGF } & DECEMBER SOLSTICE & 6.4415 & 6.4621 & 6.0880 & 12.2966 \\
\hline & MARCH EQUINOX & 5.7560 & 7.9132 & 3.4146 & 11.1347 \\
\hline & JUNE SOLSTICE & 4.5427 & 5.0331 & 1.5801 & 8.0624 \\
\hline & SEPTEMBER EQUINOX & 7.4430 & 8.6134 & 4.1673 & 10.2601 \\
\hline MEAN & & 6.0715 & 7.3363 & 3.8403 & 10.2530 \\
\hline
\end{tabular}

Table 5. Comparisons of mean of RMSE at quiet condition and mixed condition

\begin{tabular}{|lcc}
\hline \multirow{2}{*}{ Model } & \multicolumn{2}{c}{ RMSE (TECU) } \\
\cline { 2 - 3 } & Mixed Condition & Quiet Condition \\
\hline IRI-01COR & 8.222 & 6.0715 \\
NEQUICK & 7.760 & 7.3363 \\
NIGTEC & 3.378 & 3.8403 \\
IRI-PLAS & 9.731 & 10.2530 \\
\hline
\end{tabular}

\section{Results and Discussion}

\subsection{Diurnal Variations of TEC}

Figures 2-11 show the diurnal variations of the observed GPSTEC and the modelled values. In Figures 2-6, the GPS-TEC plots are represented with the legend marked 'GPS', while those of the IRI-01cor, NeQuick, NIGTEC and IRI-Plas are distinguished with legends IRI-01cor, NEQUICK, NIGTEC and IRI-Plas respectively. In Figures 7-11, the GPS-TEC plots are labelled (a) under each Figure. Those of the IRI-01cor, NeQuick, NIGTEC and IRI-PLAS are labelled (b), (c), (d), and (e), respectively.

The observed GPS-TEC in Figures 2-11 has higher values during daytime compared with nighttime values which may be attributed to the high ionization due to intense solar radiation during the daytime. The diurnal trend across most of the stations is such that the TEC rises from about the 0430-0500 LT in the morning to maximum values about $1300-1400 \mathrm{LT}$ in the afternoon, after which the TEC begins to experience a decrease till about $2300 \mathrm{LT}$ in the night. However, we see that for some stations, the TEC values remains almost constant between 1300$1500 \mathrm{LT}$, causing the diurnal curve to be flat in the afternoon. The rising of the TEC with time in the morning is gradual while its decaying in the afternoon after reaching the peak is more rapid across all the stations. The gradual increase in TEC to a maximum value at peak hours of the day at low latitudes has been attributed to solar extreme ultraviolet (EUV) ionization coupled with the vertical E X B drift (Bolaji et al. 2012). The plot shows that VTEC has higher values during daytime compared with night time values for all the seasons. The observed low nighttime values of TEC are obviously due to the absence of solar radiation at nighttime (Eyelade et al. 2017). Oron et al. (2013) explained that the nighttime decrease is due to the size of the magnetic flux tubes, which are so small that electron content in these tubes collapses rapidly after sunset in response to the low temperatures in the thermosphere at night, leading to low GPS TEC values. During sunrise, the magnetic flux tubes again get filled up because of their small volume, resulting in a sudden increase in ionization due to increasing thermospheric temperatures during sunrise (Oron et al. 2013)

The general diurnal variation pattern of observed GPS-TEC observed in Figures 2-11, with daytime maximum about local noon is in agreement with earlier works of Bagiya et al. (2009) and Rabiu et al. (2014) among others; and is a clear reflection of the augmentation of the ionosphere in consistency with the photoionization theory due to solar activity which actually maximizes about local noon. It is noteworthy that the modelled TEC follow the diurnal pattern of the observed GPS-TEC with variations in magnitudes as shown in Figures 2-11. Similar observation has been reported in the earlier works of Okoh et al. (2012) and Rabiu et al. (2014).

\subsection{Seasonal Variation}

Seasonal variations of VTEC for the year 2012, as shown in Figures 2-6, indicate that the greatest values of observed GPSTEC were recorded in the March equinox season follow by the September equinox and lower values at the June and December solstices. This equinoctial maximum is obvious on the contour maps in Figures 7a, 8a, 9a, 10a, and 11a across the five stations 
under consideration. This semiannual distribution is also noticed to be asymmetry with the maximum values in March equinox. Bolaji et al. (2013) and Rabiu et al. (2014) had observed similar semiannual variation in GPS-VTEC at some stations within Nigeria. More recently, Eyelade et al. (2017) reported that the seasonal variation in GPS TEC over Nigeria could be explained by the seasonal changes in atmospheric composition as argued by $\mathrm{Wu}$ et al. (2004) and Rama Rao et al. (2006a). They based their argument on the works of Titheridge (1974), who reported a worldwide semiannual variation in atmospheric composition, with the ratio $\mathrm{O} / \mathrm{N}_{2}$ (the relative densities of atomic oxygen and molecular nitrogen) at a maximum near the equinoxes. Also, Rama Rao et al. (2006) argued that the lower values of GPS TEC during the solstice days may be attributed to the low ionization densities due to the reduced production rates indicated by the reduced $\mathrm{O} / \mathrm{N}_{2}$ ratios owing to the increased scale height of $\mathrm{N}_{2}$ as reported by Titheridge (1974). Rishbeth et al. (2000) and the references therein attributed the seasonal variations in the ionosphere to changes in the neutral air composition due to the large-scale thermospheric dynamics, changes in atmospheric turbulence, inputs from atmospheric waves, and variations in geomagnetic activities. Also, some authors have attributed the semi-annual variation in the GPS TEC to be due to the combined effect of the solar zenith angle and geomagnetic field geometry (Olatunji, 1967; Bailey et al. 2000; Wu et al. 2004; Liu et al. 2006, 2009; Rama Rao et al.2006b; Bagiya et al. 2009; Lee et al.2010; and Eyelade, et al. 2017).

\subsection{Comparison between GPS-TEC NEQUICK-TEC, NIGTEC and IRI-PIas 2017}

IRI-TEC,

Figures 2-6 also compared the seasonal mean hourly values of observed GPS TEC with the TEC values obtained from the four models IRI-TEC, NEQUICK-TEC, NIGTEC and IRI-Plas 2017 for the year 2012. Also Figures 7-11 allowed for the comparison of the observed GPS TEC with the TEC values obtained from the four models IRI-01 cor, NeQuick, NIGTEC and IRI-Plas 2017.

It is obvious from Figures 2-6 that, for all seasons, NeQuick and NIGTEC showed good agreement with the GPS TEC at 06:00 LT but all the other models overestimated observed GPS-TEC between 00 LT- 04 LT. Both IRI-01 and NeQuick overestimated observed GPS-TEC throughout the day. A good agreement is observed between GPS-TEC and NIGTEC at 5:00 LT. IRI and NeQuick overestimated and underestimated TEC values respectively. The models show very poor agreement with observed GPS-TEC values at midnight. IRI model overestimated VTEC values at all hours of the day. NIGTEC model records very close agreement with the observed GPS-TEC, while NeQuick only shows good agreement at pre-sunrise hours between 05:00 - 07:00 LT. The IRI-Plas 2017 overestimated the observed GPS-TEC most of the times except few instances of underestimation at about 1200-1700 LT during March equinox, June solstice and September equinox at ABUZ; and 1400 -1600 LT during March equinox, June solstice and September equinox at BKFP.

Generally, all the models captured the diurnal variation pattern of the processed GPS-VTEC as revealed in Figures 2-11, but demonstrated varying deviations from the magnitudes at different times of the day. The variation pattern is such that VTEC gradually rises in the morning and peak in daytime, follow by a steep decrease towards the sunset time. The night time values are generally lower than the daytime values.

In addition, the contour maps of the daily hourly variation throughout the years for the observed GPS-TEC and all the four models under consideration in Figures 7-11 clearly show that only NeQuick and NIGTEC models effectively captured the annual distribution pattern of the observed GPS-TEC across the stations. The IRI-01cor and the IRI-Plas 2017 model distributions are obviously over-smoothed with respect to the GPS-TEC. These clearly indicated NIGTEC and NeQuick, unlike IRI-01cor and IRI-Plas 2017 models, captured the seasonal redistribution of ionospheric currents in response to seasonal variability of the drivers of the ionosphere.

\subsection{Root Mean Square Errors of IRI-01cor, NEQUICK, NIG-TEC and IRI-PIas 2017 from GPS- TEC}

Table 2 reports the RMSE values of various models across the stations and seasons. The lower the RMSE, the better the performance of the model. At ABUZ, the model with the lowest RMSE is NIGTEC with values of 4.795 (December Solstice), 3.215 (March Equinox), 1.919 (June Solstice) and 2.936 (September Equinox). The next higher RMSE across all the season is found in the NeQuick model with the following values: 5.776 (December Solstice), 7.430 (March Equinox), 5.833 (June Solstice) and 8.128 (September Equinox), while IRI01 model recorded the RMSE values of 13.547 (December Solstice), 12.328 (March Equinox), 11.088 (June Solstice) and 11.541 (September Equinox). The IRI-Plas 2017 has the following RMSE at the respective seasons: 8.321 (December Solstice), 8.566 (March Equinox), 6.344 (June Solstice) and 6.538 (September Equinox).

At BKFP, the model with the lowest RMSE is NIGTEC with values of 4.175 (December Solstice), 3.411 (March Equinox), 2.010 (June Solstice) and 3.197 (September Equinox). IRI-01cor model recorded a slightly higher RMSE values of 5.883 (December Solstice), 5.265(March Equinox), 3.767 (June Solstice) and 5.879 (September Equinox), while NEQUICK has the highest RMSE values of 5.631 (December Solstice), 8.207 (March Equinox), 7.318 (June Solstice) and 7.061 (September Equinox). The IRI-Plas 2017 has the following RMSE at the respective seasons: 8.653 (December Solstice), 8.721 (March Equinox), 5.996 (June Solstice) and 7.815 (September Equinox).

At CLBR, the model with the lowest RMSE is NIGTEC with values of 4.354 (December Solstice), 3.541 (March Equinox), 3.288 (June Solstice) and 3.197(September Equinox). IRI-01cor model recorded a slightly higher RMSE values of 6.291 (December Solstice), 7.771 (March Equinox), 7.318 (June Solstice) and 7.061 (September Equinox) while NEQUICK has the highest RMSE values of 10.335 (December Solstice), 7.772 (March Equinox), 10.337 (June Solstice) and 9.138 (September Equinox). The IRI-Plas 2017 has the following RMSE at the respective seasons: 17.110 (December Solstice), 19.268 (March Equinox), 11.115 (June Solstice) and 13.242 (September Equinox).

At FUTY, the model with the lowest RMSE is NIGTEC with values of 3.621 (December Solstice), 3.823 (March Equinox), 2.624 (June Solstice) and 3.221 (September Equinox). IRI-01cor model recorded a slightly higher RMSE values of 6.074 (December Solstice), 5.514 (March Equinox), 4.697 (June Solstice) and 6.679 (September Equinox), while NEQUICK has the highest RMSE values of 6.167 (December Solstice), 7.778 (March Equinox), 6.203 (June Solstice) and 7.746 (September Equinox). The IRI-Plas 2017 has the following RMSE at the respective seasons: 9.311 (December Solstice), 9.369 (March Equinox), 8.413 (June Solstice) and 8.952 (September Equinox).

At OSGF, the model with the lowest RMSE is NIGTEC with values of 4.707 (December Solstice), 3.272 (March Equinox), 2.287 (June Solstice) and 3.037(September Equinox). IRI-01cor model recorded a slightly higher RMSE values of 4.981 (December Solstice), 5.458 (March Equinox), 4.656 (June Solstice) and 6.624 (September Equinox) while NEQUICK has the highest RMSE values of 6.462 (December Solstice), 7.699 (March Equinox), 6.079 (June Solstice) and 8.135 (September Equinox). The IRI-Plas2017 has the following RMSE at the respective seasons: 10.036 (December Solstice), 10.036 (March Equinox), 8.044 (June Solstice) and 9.207 (September Equinox).

Summarily from Tables 2 , the RMSE values computed for the four models show that NIGTEC has the lowest values for all the seasons ranging from 1.134 to 4.707 . IRI-01cor values range from 3.767 to 9.262 , IRI-Plas 2017 values range from 5.996 to 19.268 , 
while NEQUICK values vary from 5.398 to 9.920 . The mean RMSE of the NeQuick, IRI-01Cor, NIGTEC and IRI-Plas 2017 models are $8.222,7.760,3.378$ and 9.731 respectively. It is obvious from the values obtained that the NIGTEC has the lowest mean RMSE, while the IRI-Plas 2017 has the highest mean. It therefore implies that the NIGTEC model performs better than IRI-01cor, NEQUICK and IRI-Plas 2017 models in terms of prediction error.

\subsection{Comparison of performance of models at quiet condition only}

It is obvious from Figures $12,13,14,15$, and 16 that diurnal variation of each of the models, that is: NIGTEC, IRI-01cor, NEQUICK and IRI-Plas 2017; follow the diurnal trend of measured GPS TEC with variances in magnitudes at different hours just as the situation when disturbed and quiet conditions were grouped together in Figures $2-6$. The diurnal variation maximizes at daytime between 1000 and 1400 LT across all the models. It is observed that NIGTEC model values are the closest to the measured GPS TEC values across the stations and in all seasons.

The standard deviation of various TEC models across the seasons on quiet condition, as shown in Table 3, is such that NIGTEC has the lowest values $(0.8974-3.4396)$, followed by IRI-Cor (1.9139 - 5.0563). NEQUICK and IRI-PLAS have values 2.5172 to 6.90211 and 3.2387 to 6.3755 respectively. The standard deviation in this case is a measure of inter hourly variability of a particular quantity within a batch (Ayorinde et al. 2016). The implication is that NIGTEC model is more stable in predicting hourly GPS TEC in the region of study.

As can be observed from Table 4, the RMSE values obtained for the four models on quiet condition show that NIGTEC has the lowest values for all the seasons ranging from 1.4154 to 6.3263 . IRI-01cor values range from 3.4597 to 9.5522, IRI-Plas 2017 values range from 3.6886 to 19.1240 , while NEQUICK values vary from 4.9988 to 10.5688 . The mean RMSE of the NIGTEC, IRI-01Cor, NeQuick, and IRI-Plas 2017 models for quiet days only are $3.8403,6.0715,7.3363$, and 10.2530 respectively; this shows an increasing order. Table 5 compares the mean RMSE at both geomagnetically quiet condition and when all the days of the year 2012 were engaged in the work. With mean values of RMSE as 3.378 and 3.8403 for mixed condition and geomagnetically quiet condition respectively, NIGTEC returned the lowest RMSE values at all conditions. This clearly shows that, even under geomagnetically quiet condition, the NIGTEC model performs better than IRI-01cor, NEQUICK and IRI-Plas 2017 models in terms of predicting error.

\section{CONCLUSIONS}

The following conclusions are drawn from this work:

1. VTEC values are generally high during daytime when compared to night-time values. TEC values increased from 05.00 UT and reaches its maximum value during 12.00-15.00 UT.

2. Highest daytime values of VTEC was recorded in September equinox, while lowest value was observed during June solstice.

3. The NIGTEC model has better agreement with the observed VTEC when compared with the IRI-01cor, NEQUICK and IRIPlas 2017 models especially during the pre-Sunrise period.

4. . NIGTEC returned the lowest mean values of RMSE of 3.378 TECU and 3.8403 TECU for all days and geomagnetically quiet condition respectively. Thus the NIGTEC model performed better than IRI-01 cor, NEQUICK and IRI-Plas 2017 models in terms of prediction error irrespective of geomagnetic condition.

5. Annual distributions of TEC computed from the IRI and IRIPlas models are visibly over-smoothed when compared to the GPS-TEC. The NeQuick and NIGTEC models effectively captured randomness represented in the annual distribution pattern of the observed GPS-TEC across the stations. These clearly indicated NIGTEC and NeQuick, unlike IRI-01 cor and
IRI-Plas2017 models, captured the seasonal redistribution of ionospheric currents in response to seasonal variability of the drivers of the ionosphere.

6. It is noteworthy that the modelled TEC obtained from all the four models, at both geomagnetically disturbed and quiet times, follow the diurnal pattern of the observed GPS-TEC with variations in magnitudes.

\section{ACKNOWLEDGEMENTS}

Authors are grateful to the Office of the Surveyor General of the Federal Government of Nigeria for making the NIGNET GPS data available and Dieter Bilitza including the IRI Team for the IRI models. We also appreciate the Aeronomy and Radio Propagation Laboratory of Abdus Salam International Centre for Theoretical Physics ICTP, Trieste, Italy for granting access to NeQuick package. Special thanks to the Centre for Atmospheric Research, National Space Research and Development Agency, Nigeria for free access to the NIGTEC model and for R \& D grant in support of this research. The anonymous reviewers and editorial team are greatly acknowledged for their excellent reviews.

\section{REFERENCES}

Adewale, A.O., Oyeyemi, E.O., Adeniyi, J.O., Adeloye, A.B. and Oladipo, O.A.: 2011. Indian J. Radio Space Phys. 40, 21-25.

Adewale, A.O., Oyeyemi, E.O., Cilliers, P.J., McKinnell, L.A. and Adeloye, A.B.: 2012. Adv. Space Res. 49, 316-326.

Appleton, E.V. (1946): "Two anomalies in the ionosphere". Nature. 157, 691-693

Arikan, F., Seymur, S., Hakan, T., Orhan, A., Gulyaeva, T.L.: 2016, Geodesy and Geodynamics. 7, 1-10.

Ayorinde, T. T., Rabiu, A.B., and Amory-Mazaudier, C.: 2016. Atmos and Solar-Terrestrial Physics J. 145, 21-33

Bagiya, M. S., Joshi, H. P., Iyer, K. N., Aggarwal, M., Ravin-dran, S., and Pathan, B. M.: 2009, Ann. Geophys. 27, 1047-1057,

Bailey, G. J., Su, Y. Z., and Oyama, K.-I.: 2000, Ann. Geophys. 18, 789-798.

Bhuyan, P.K. and Borah, R.R.: 2007, Adv. Space Research. 39, 830-840.

Bidaine, B., Warnant, R.: 2010, Adv. Space Res. 45, 1122-1128.

Bilitza, D 1990.: International Reference lonosphere 1990, National Space Science Data Center, 90-22, Greenbelt Maryland

Bolaji, O. S., Adeniyi, J. O., Adimula I. A., Radicella S. M., and Doherty, P. H.: 2013, J. Atmos. Sol. Terr. Phy. 98, 1-11

Bolaji, O. S., Adeniyi, J. O., Radicella, S. M., and Doherty, P. H.: 2012, Radio Sci. 47

Breed, A.M., A. L. Goodwin, A. M. Vandenberg, E. A. Essex, K. J. W. Lynn and Sylby J.W.: 1997, Radio Sci. 32 (4), 1635-1643.

Coisson, P., Radicella, S.M., Nava, B. and Leitinger, R.: 1995, J. Atmos. Sol. Terr. Phys. 70, 901-906.

Di Giovanni, G. and Radicella, S.M.: 1990, Adv. Space Res. 10(11): 27-30

Eleman, F.: The geomagnetic field, in: Cosmical Geophysics, Chap.3, edited by: Egeland, A., Holter, O., and Omholt, A., Scandinavian University Books, Oslo, 45-62, 1973.

Eyelade, V.A., Adewale, A.O., Akala, A.O., Bolaji, O.S., and Rabiu, A.B.: 2017, Ann. Geophys. 35, 701-710

Ezquer, R.G., Scida, L.A., Orue, Y.M., Nava, B., Cabrera, M.A.and Brunini, C.: 2017, Adv. Space Res. 34-45

Gopi, S.:2010, Rinex GPS-TEC program, version 1.45. Boston College. Satellite Navig. Sci and Tech for Africa Workshop (23rd March-9th April 2009, ICTP, Trieste, Italy)

Gulyaeva, T.L.and Bilitza, D.: 2012, Towards ISO Standard Earth lonosphere and Plasmasphere Model. In: Larsen R.J., editor. New developments in the standard model, Nova Science Publishers. p. 39.

Habarulema, J. B.: 2010, A contribution to TEC modelling over southern Africa using GPS data, Ph.D. Thesis, Rhodes Univ., Grahamstown, South Africa.

Habarulema, J.B., McKinnell, L and Cilliers, P.J.: 2007, J. Atmos. and Sol.-Terr. Phy. 69, (15): 1842-1850.

Lee, C. C., Chuo, Y. J., and Chu, F. D.: 2010, J. Atmos. Sol.-Terr. Phy. 72, 207-212.

Liu, L. and Chen, Y.: 2009, J. Geophys. Res. 114. 
Liu, L., Wan, W., Ning, B., Pirog, I. M., and Kurkin, V. I.: 2006, J. Geophys. Res. 110.

Mannucci, A. J., Wilson, B. D., and Edwards, C. D.: 1993, A new method for monitoring the Earth's ionospheric total electron content using the GPS global network, Institute of Navigation, 1323-1332, Salt Lake City, Utah

MigoyaOrue', Y.O., Radicella, S.M., Coi”sson, P., Ezquer, R.G., and Nava, B.: 2008, Adv. Space Res. 42, 757-762.

Misra, P. and Enge, P.: 2006, Global Positioning System: Signals, Measurements, and Performance. 2nd Edition, GangaJamuna Press, Lincoln. International Journal of Geosciences. p. 569.

Mitra, S.K.: 1946, Geomagnetic control of region F2 of the ionosphere. Nature. 158:668-669.

Okoh, D., Eze, A., Adedoja, O., Okere, B. and Okeke, P.N.: 2012, Nigeria. Space Weather. 2, 10.

Okoh, D., McKinnell, L., Cilliers, P., Okere, B., Okonkwo, C. and Rabiu, B.: 2015, Adv. in Space Research. 55:1941-1947

Okoh, D., Owolabi, O., Ekechukwu, C., Folarin, O., Arhiwo, G., Agbo, J., Bolaji, S. and Rabiu, B.: 2016, Geod. Geodyn. 7, 19-31,

Olatunji, E. O.:1967, J. Atmos. Terr. Phys. 29, 277-285.

Olwendo, O. J., Baki, P., Cilliers, P. J., Mito, C, and Doherty, P.: 2013, Adv. Space Res. 52, 1770-1779.

Oron, S., Ujanga, F. M. D., and Ssenyonga, T. J.: 2013, Indian J. Radio Space. 42, 7-17

Rabiu, A. B., Mamukuyomi, A. I., and Joshua, E. O.: 2007, B. Astron. Soc. India. 37, 607-618.

Rabiu, A. B., Adewale, A.O., Abdulrahim, R. B., Oyeyemi, E.O.: 2014, Advances in Space Research. 53, 1290-1303

Rama Rao, P. V. S., Gopi Krishna, S., Niranjan, K., and Prasad, D. S. V. V. D.: 2006a, Ann. Geophys. 24, 3279-3292

Rama Rao, P. V. S., Gopi Krishna, S., Niranjan, K., and Prasad, D. S. V. V. D.: 2006, Ann. Geophys. 24, 1567- 1580.

Rama Rao, P. V. S., Niranjan, K., Prasad, D. S. V. V. D., Gopi Krishna, S. and Uma, G.:2006, Annals of Geophysics, 24, 2159-2168.

Rishbeth, H., Müller-Wodarg, I. C. F., Zou, L., Fuller-Rowell, T. J., Millward, G. H., Moffett, R. J., Idenden, D.W., and Aylward, A. D.: 2000, Ann. Geophys. 18, 945-956

Tariku, Y. A.: 2015, Earth, Planets and Space 67,140.

Titheridge, J. E.: 1974, J. Atmos. Terr. Phys.36, 1249-1257

Wu, C. C., Fryb, C. D., Liu, J. Y., Lioud, K., and Tseng, C. L.: 2004, J. Atmos. Sol.- Terr. Phys. 66, 199-207 